\title{
MERCOSUL x BRASIL: ANÁLISE DA SOBERANIA FISCAL
}

\section{Maria de Fátima Ribeiro* Juliana Kiyosen Nakayama*}

SUMARIO: 1. Introdução, 2. Soberania e federalismo fiscal. 3. Conclusĩo. 4. Bibliografia.

SUMMARY: 1. Introduction. 2. Sovereignty and Fiscal Federalism. 3. Conclusion. 4. Bibliography.

SUMARIO: 1. Introducción. 2. La soberania y el Federalismo Fiscal. 3. Conclusión. 4. Bibliografía.

RESUMO: O presente estudo tem o objetivo de analisar o conceito de soberania, da existência ou não da soberania tributatia no Brasil e suas implicações com o pacto federativo e competências tributárias face ao MERCOSUL. Ressalta a preocupação de uma das liberdades do bloco, a livre circulação de bens e de serviços. A soberania do Estado alberga a soberania fiscal ou tributária. Em âmbito internacional, a soberania fiscal ou tributáriz reflete-se como capacidade plena de um Estado diante dos demais no cenário internacional. O Estado tem soberania fiscal quando edita suas leis, quando a sua vontade ća última a prevalecer quanto aos seus administrados, e a soberania fiscal ultrapassa o território do Estado, quando sua competência tributária alcança seus contribuintes onde quer que eles estejam. A aplicabilidade das normas constantes nos tratados decorre do postulado da soberania, como abordou-se acima, cujo conceito revela um

\footnotetext{
"Doutora em Direito Tributánio pela PLC SP. Professora e Coordenadora do Mestrado em Direito Negocial da Unirersidade Estadual de Londrina e do curso de Direito da Faculdade Paranatse. E-mail: mateidatictcon.br

whestre en Dirito Negocial da Universidade Estadual de Londrina. Professona da Faculdade Paramense, E-mail: juakayama Stercomtel.combo
} 
caráter de supremacia, concemente ao poder jurídico, distinguindo-se da soberania do Estado dirigida a todos de seu territónio e nas relaçóes recíprocas entre os Estados, $A$ seguir, referir-se-á ao assunto tratado de forma ampla $e$ depois do tratado en matéria tributária. Tais implicaçôes refletem na Reforma Tributáma do Brasil com os ajustes assumidos pelo Bloco mercosulno.

ABSTRACT: The present study has as objective to analyze the concept of sovereignty, the existence or not of the soveregnty tax in Brazil and its implications on the federative pact and abilities taxes on MERCOSUR. It stands out the concern of one of the freedoms of the block, the free circulation of goods and services. The sovereignty of the State lodges the fiscal sovereignty or tax. In international scope, the fiscal soveregnty or tax is reflected as full capacity of a State ahead of excessively in the international scene. The State has fiscal sovereignty when it edits its laws, when its will is the last one to prevall how much to managed its, and the fiscal sovereignty exceds the territory of the State, when its ability tax reaches its contributors where it wants that they are. The applicability of the constant noms in International Treatys elapses the postulate of sovereignty, as concen the juridical power, which its concept discloses a supremacy character, distinguishing itself from the sovereignty of the State directed to all of its territory and in the reciprocal relations between the States. After that, treaty and the tax treaty are analysed more deeply. Such implications reflect in Brazil's Reformation Tax and the adjustments assumed by MERCOSUR's members.

RESUMEN: El presente estudio tiene el objetivo de analizar el concepto de la soberania, la existencia o no del impuesto de la soberania en el Brasily sus implicaciones en lo pacto federativo de los impuestos y en las competencias tributarias en el MERCOSUR. Resalta la preocupación con la libre circulación de mercaderias y servicios. La soberania del estado aloja la soberanía del impuesto fiscal. En alcance internacional, la soberanta o el impuesto fiscal se reflejan como capacidad completa de un estado delante excesivamente adentro de la escena intemacional. El estado tiene soberania fiscal cuando él edita sus leyes, cuando su voluntad debe prevalecer cuánto a sus administrados, y su soberanfa fiscal exceder su ternitorio, cuando su competencia tributaria alcanza su contribuidor donde él desear que estuviera. La aplicabilidad de las nomas constantes en tratados transcurre del postulado de la soberania, cuyo concepto revela un carácter de supremacía, concerniente al poder juridico, distinguiendo de la soberania del estado dirigida a todos de su territorio y en las relaciones reciprocas entre los estados. En seguir, lo tratado es analizado más ampliamente y después del tratado en materia tributaria será mencionado. Tales implicaciones reflejan en la Reforma Tributaria del Brasil con los ajustes asumidos para el MERCOSUR.

PALAVRAS-CHAVE: Soberania fiscal. Brasil. MERCOSUL.

KEY-WORDS: Fiscal sovereignty. Brazil. MERCOSUR.

PALABRASLLAVES: Soberanía fiscal. Brasil. MERCOSUR. 


\section{Introdução}

A globalização tem sido associada ao processo de integração das economias mundiais, relacionado à flexibilização dos movimentos de mercadorias, capitais e pessoas entre países.

Discute-se nessa contingência a soberania dos Estados envolvidos nesse processo de globalização:

A harmonização tributária torna-se, então, o processo mediante o qual os governos dos países envolvidos nos processos de integração, acordarão sobre a estrutura e o nível de coerção de seus sistemas tributários, minimizando os efeitos da tributação sobre as decisões de consumo e produção.

Investido de soberania, o Estado tem o poder de dispor sobre o sistema tributário. Heleno Torres utiliza a expressão - soberania tributária para expressar o poder institucionalizado que coloca o Estado como sujeito da ordem mundial, proporcionando-the autonomia e independência na determinação dos fatos tributáveis e nos procedimentos de arrecadação e fiscalização dos tributos, nos termos das auto limitações de fontes originariamente internas e constitucionais, bem como de fontes internacionais. $^{2}$

O Brasil, como um Estado Federal, tem a competência constitucional tributária distribuída exaustivamente na Carta Política entre a União, Estados, Distrito Federal e Municípios. Essa descentralização de competência (no âmbito interno) o faz diferente de outros Estados, face à autonomia dos entes políticos internos.

Dessa forma, questiona-se, se o conteúdo de um tratado internacional prevalece sobre a competência tributária dos Estados-membros, do Distrito Federal e dos Municípios, resguardada a exclusividade da competência tributária para as unidades da Federação.

\footnotetext{
1 Globalização ou mundialização á a interdependência social, associação social, reordenamento do tempo e da distância social como umas das consequiências fundamentais da modernidade. Entende-se como processo de alargamento dos métodos de conexăo entre diferentes contextos sociás ou regióes que se convertem em uma rede ao longo de toda a superficie da tera. Pode-se definir como a intensificação das relaçóes sociais em todo o mundo pelas quais se enlaçam lugares distantes, de tal maneira que os acontecimentos locais estão determinados por acontecimentos que ocorrem a muitos quilômetros de distância e viceversa. A denominaçăo globalização é usada pelos paises anglo-saxónicos e o termo mundialização usados pelos europeus. In: PIMENTEL, Luiz Otávio. Cenário intemacional, Direito e sociedade no processo de mundializaçâo. In.: Mercosul no cenário intemacional: Direito e Sociedade. Curitiba: Juruá, 1998 , vol.2. p.365-380

2 TORRES, Heleno. Pluritributação Internacional sobre as rendas das empresas, RT, SP, 2001, p. 66/7. 


\section{Sobcrania e federalismo fiscal}

A ordem internacional atual está ligada ao conceito de soberania. Com a interdependência crescente entre os Estados, diminui a efetiva capacidade de autodeterminação. O princípio de autodeterminação dos povos traz uma idéia de que a cada nação deve corresponder um Estado soberano ${ }^{3}$.

Nesse contexto, serão abordados os conceitos de soberania e soberania fiscal ou tributária.

Explica Heleno Torres que a expressão soberania tributária deve ser admitida como a designação da qualidade do poder que coloca o Estado como sujeito da ordem mundial, que the proporciona autonomia e independência na determinação dos fatos tributáveis e que só admite autolimitações de fontes originariamente internas e constitucionais. ${ }^{4}$ Ressalta também que a contraface da soberania tributária, demonstra o seu aspecto negativo, através do qual a exclusividade de autodeterminação refuta qualquer possibilidade de aplicação de atos de autoridade e leis alienígenas.

Esse espírito de cooperação entre as nações demonstra que o que norteia as ações na política internacional não é mais o individualismo estatal, ou nacional, mas o sentimento de cooperação e a necessidade entre os povos. Tem-se ai as relações internacionais interindependentes.

A teoria da tributação, segue esta mesma linha de raciocínio. A imposição absoluta e indiscriminada começa a perder força. Juntamente com os tratados internacionais que versem sobre os direitos humanos, sobre comércio, firmam-se convenções internacionais sobre tributação da renda, sobre a transferência de preços, evitando com isso a dupla tributação da renda diminuindo a força impositiva do Estado.

Isso significa dizer que, face à cooperação econômica entre as nações, os Estados renunciam uma parcela dos recursos financeiros que teriam direito. $\mathrm{O}$ tributo passa a ter, prioritariamente outra função, diferente da arrecadatória, embora o tributo figure como uma das principais fontes de receita.

Não há dúvidas de que o tributo tem sua importância fiscal, servindo como base de arrecadação para o Estado. No entanto, a função extrafiscal

\footnotetext{
${ }^{3}$ DALLARI, Pedro. Constituição e relaçōes exteriores. São Paulo: Saraiva, 1994, p.164-165

4 TORRES, Heleno. Pluritributação Intemacional sobre as Rendas das Empresas. São Paulo, RT, 1997, p. 49.

Idem, ibidem, p. 49 
do tributo vem sendo implementada em diversos Estados. Os Estados se comprometem a não manter direitos alfandegários entre si, e também a não discriminar os produtos dos parceiros com incentivo aos seus próprios ou alíquotas maiores para aqueles, com a função de incentivar o comércio intra bloco. ${ }^{6}$

Houve o abandono da soberania absoluta para utilizar-se do termo independência. A palavra utilizada no sentido moderno, soberania relativa, para designar o mais alto poder, conforme enuncia Celso Albuquerque Mello7.

A rigor, Celso Albuquerque $\mathrm{Mello}^{8}$, entende ainda, que a tendência atual é a soberania existir como um conceito meramente formal. Ou seja, o Estado soberano é aquele que se encontra direta e imediatamente relacionado ao Direito internacional público. $\mathrm{O}$ conteúdo da soberania é cada vez menor na medida da internacionalização da vida econômica, social e cultural.

Assim, não se pode mais aplicar à soberania a noção de soberania absoluta, ilimitada. Isto não traz como efeito a caracterização do termo, mas uma flexibilização, uma relativização, que se dá tanto no plano externo quanto no interno dos Estados, conforme afirma Roberto Luiz Silva."

Continuando, destaca que depois de afirmado o fato da soberania não ser mais considerada absoluta e ilimitada, discute-se então, com a supranacionalidade, o princípio da indivisibilidade, defendendo-se a tese da soberania dividida ou soberania repartida. ${ }^{10}$

Todavia, a expressão soberania designa a capacidade para dirigir a vida do ente social correspondente, e, da mesma forma, como a autoridade que possui o Estado para decidir, em última alçada, sobre as questões da sua competência, não é poder absoluto e sim subordinado ao Direito das gentes, no dizer de Hildebrando Accioly ${ }^{11}$. Diz-se soberania interna

FERNANDES, Edison. Nomas Tributárias do MERCOSUL in O Direito Tributário no MERCOSUL, Forense, RJ, 2000, p. 191.

"Mello, Celso Duvivier de Albuquerque. Curso de Direito internacional público. $11 \mathrm{ed}$ rey, aum. Rio de Janciro: Renovar, 1997, vol. 1, p.338-340.

* Idem. Direito constitucional internacional: uma introduçăo. Rio de Janeiro: Renovar, 1994, p.21

"Tal afmativa faz parte do artigo apresentado pelo professor recentemente em Londrina quando da realizaça do X Encontro de Estudantes de Direto do MERCOSUL sobre: Da Análise da Soberania Estatal sob o prisma do Direito Comunitário e da Integração, publicado nos Anais, UNIFIL, Londrina, 2002, p. 920.

${ }^{10} \mathrm{Idem}$, ibidem, p. 920. De acordo com essa nova teoria, a antiga noção de soberania seria dividida em duas: soberania qualitativa e soberania quantitativa. A primeira, assim como as prerrogativas da personalidade jurídica em sede de direito privado, é intocável, sendo que as competências a ela relativas nẫo podem ser delegadas a nenhuma organização, sob pena de haver a própria descaracterização do Estado soberano enquanto tal. Já a segunda, assimilada à capacidade jurídica de exercício de diretos, é passável de ser transferida Antonio Fernando Diniz Teixera - A Natureza das Comunidades Européias (estudo politico juridico) Coimbra, Livraria Almedina, 1993, citado pelo Prof, Roberto Luiz Silva na obra mencionada nota it 9.

"ACCIOLY, Hildebrando. Manual de Direito internacional público. 11ed. São Paulo: Saraiva, 1991 9a tiragem. Revista por Geraldo Eulálo do Nascimento e Stiva, p.16 
ou supremacia do Estado sobre o cidadão, a autonomia e a soberania externa, a independência.

No entendimento de Constantino Morati ${ }^{12}$, autonomia quer dizer a liberdade de determinação consentida a uma sujeito, resultando no poder de dar a si mesmo a lei reguladora da própria conduta, ou o poder de prover o atendimento dos proprios interesses e por isso gozar e dispor de meios necessários para obter uma satisfaça harmônica e coordenada dos referidos interesses.

Com relaç̃o aos blocos internacionais, podese afirmar que não há perda de soberania, mas delegação ou transferência em matérias específicas, sendo que os interesses prioritários passarão a ser os do bloco e não os interesses nacionais.

Em vista disso, José Eduardo Soares de Melo $^{13}$ explicita que a soberania é limitada pelo próprio ordenamento legal, no plano intemo pelos direitos e pelas garantias individuais e no âmbito externo pela ordem juridica internacional.

A propósito, a soberania aparece como fonte das competências que o Estado recebe do Direito internacional, que não são ilimitadas, mas nenhuma outra entidade as detém em maior grau. A soberania permanece, de fato, como o atributo fundamental do Estado. Enfim, a independência do Estado não está, de modo algum, comprometida, nem a sua soberania violada pela existência de obrigaçöes internacionais do Estado ${ }^{14}$.

Após o surgimento das primeiras Constituiçöes, pode-se falar em soberania juridica do Estado. Surge, então o Estado como sujeito da ordem internacional com verdadeira soberania estatal.

Conforme estudos de Dominique Villemot ${ }^{15}$ a soberania estatal manifesta-se pelo exercício de três poderes: cunhar moedas, exigir tributos e dispor de forças armadas. $O$ autor destaca que a soberania fiscal é um elemento ultra-sensivel da soberania nacional. ${ }^{16}$

Ressalta por sua vez, Heleno Tôrres ${ }^{17}$ que a soberania tributária, como manifestação negativa, não permite a interferência de outras soberanias

\footnotetext{
12 MORAT, Constantino. Instituzioni di diritto pubblico. 7 ed. Padova: Cedam, 1968, v.2, p. 694. apud REIS, Elcio Fonseca. Federalismo fiscal: competência concorrente e normas gerais de Dixeito tributário. Belo Horizonte: Mandamentos, 2000

${ }^{13}$ MELO, José Eduardo Soares de. ICMS teoria e prática, 4 ed. atualizada com a LC 102/2000. São Paulo: Dialética, 2000, p.262

it DINH, Ngiryen, DAILLIER, Patrick, PELLET, Alain. Diteito intemacional público, trad. por Vitor Marques Coelho. Lisboa: Fundaçăo Calouste Gulbekian, 1999. p. 384385.

Is VILLEMOT, Dominique, L'harmonasition fiscale européenne. Paris: Presses Universitarires de France, 1995, p.3. In: FALCAO Maurin Almeida. Elementos de reflexäo para harmonização tributária no Metcosul. Monografia cedida pelo autor, vencedora do Mercoprêmio legislaçäo em 2000, p. 36 is - Id., ibidem, p. 36 .

${ }_{17}$ TORRES, Heleno. Pluritributação intenacional sobre as rendas de empresas. 2 ed. rev, atual. e ampl São Paulo: Revista dos Tribunais, 2001, p. $64-68$
} 
tributárias sobre o funcionamento do seu sistema tributário, e, que, ain$\mathrm{da}$, é aquele poder institucionalizado que coloca o Estado como sujeito da ordem mundial, proporcionando autonomia e independência na determinaçấo dos fatos tributáveis e nos procedimentos de arrecadação e de fiscalização dos tributos, nos termos das auto limitações de fontes originariamente internas e constitucionais e de fontes internacionais. Entende-se, ainda, a soberania tributária como princípio fundamentador da aplicabilidade das normas tributárias internas de um Estado.

Para Louis Cartou ${ }^{18}$, em derradeira análise, menciona-se que a soberania fiscal pode ser definida como sendo o poder de editar um sistema de impostos, seja legislativo ou regulamentar, com autonomia técnica em relação aos sistemas suscetíveis de entrar em concorrência com ele.

Acrescenta Gerd Willi Rothmann ${ }^{19}$ que a soberania fiscal do Estado ultrapassa o seu território para alcançar pessoas que se encontram fora do seu territótio. Não há correlação necessária entre soberania fiscal e soberania territorial. Assim, tecnicamente, o Estado poderá estender a esfera de sua competência tributária muito além do seu território, o que acontece freqüentemente na prática.

Consoante se vê, segundo Betina Treiger Grupenmacher" ${ }^{20}$, a soberania do Estado alberga a soberania fiscal ou tributária. Esta é a faceta da primeira e reflete na órbita interna um poder de supremacia do Estado diante do indivíduo, quando do exercício da competência tributária. Em âmbito internacional, a soberania fiscal ou tributária reflete-se como capacidade plena de um Estado diante dos demais no cenário internacional.

É possível observar que a soberania tributária não está ligada, necessariamente, ao conceito de soberania territorial. O Estado tem soberania fiscal quando edita suas leis, quando a sua vontade é a última a prevalecer quanto aos seus administrados, e, igualmente, como já mencionado, a soberania fiscal ultrapassa o território do Estado, quando sua competência tributária alcança seus contribuintes onde quer que eles estejam.

\footnotetext{
is CARTOU, Louis. Droit fiscal international et europétn. 2ed. Paris; Precis Dalloz, 1986, p.13. apud FALCÃO, Maurin Almeida. Elementos de teflexão para harmonização tributária no Mercosul. Monografia cedida pelo autor, vencedora do Mercopretrio legislação em 2000, p. 36

19 ROTHAMAN, Gerd Willi. Consideraçöes sobre extensão e limites do poder de tributar. NOGUEIRA, Ruy Barbosa (org.). Estudos tributários. São Paulo: Resenha Tributária, 1974, p.217. Apud VALADAO Marcos Aurélio Pereira. Limitaçôes do poder de tributar e tratados internacionais. Belo Horizonte: Del Rey, 2000. p.196-197

27. GRUPENMACHER, Betina Treiger. Tratados internacionais em matéria tributána e ordem intema. São Paulo: Dialetica, 1999, p. 22-23. A Professora Betina escreve com propriedade, fartamente, sobre soberania tributária segundo uma visão tradicional passando por ampla e conceituada doutrina até abordar a necessidade de um novo conceito de soberania.
} 
Por tudo isso, a aplicabilidade das normas constantes nos tratados decorre do postulado da soberania, como foi abordado, cujo conceito revela um caráter de supremacia, concernente ao poder jurídico, distinguindo-se da soberania do Estado dirigida a todos de seu território e nas relações recíprocas entre os Estados.

O Estado federal introduziu modificações profundas nas relações jurídicas entre os seus componentes, dando surgimento a uma nova entidade, que é o Estado-membro, considerado por alguns como uma forma de organização politica. Bernard Schwartz ${ }^{21}$ pronuncia que o termo federalismo é usado para descrever qualquer organização em que estados independentes concordam em delegar poderes a um governo comum com vista a Constituições inteiramente novas, mesmo dos próprios Estados.

É bem verdade que o federalismo, no entendimento de Carlos Closa ${ }^{22}$, deve ser entendido como doutrina definida por um objetivo observando dois destinos; por um lado, vincula-se aos aspectos da práxis política desinteressada das interpretações filosóficas e científicas do fenômeno, e, de outro, preocupa-se com a formulação de uma estratégia política que permita chegar ao objetivo final almejado.

Manifesta-se Konrad Hesse ${ }^{23}$ que o Estado federal deriva da lei fundamental e serve para conservar a multiplicidade regional e formação da unidade federativa. Federalismo, como princípio fundamental político, expressa a livre unificação de totalidades políticas diferenciadas, com os mesmos direitos, em regras regionais que devem ser unidas para colaboração comum. Tal ordem federativa pode servir à divisão de um corpo global político que deve ser preservado pela construção federativa da desintegração completa.

Dentro desse arcabouço, a Federação brasileira ${ }^{24}$ surgiu após sessenta e sete anos de organização unitária como Estado independente. Quando do decreto, Reino Unido Brasil-Portugal, o Brasil estava

\footnotetext{
2 Apud REIS, Elcio Fonseca. Federalismo fiscal. Belo horizonte: Mandamentos, 2000. p. 25-26.

22 CLOSA, Carlos. Sistema polícico de la Unión Europea. Madrid: Complutense, 1997. Apud OLIVEIRA, Odete Maria de. Relações internacionais: estudos de introdução. Curitiba: Juruá, 2001, p. 173-174 ${ }_{23}$ HESSE, Konrad. Elementos de Direito constitucional da República Federal da Alemanha. Luis Afonso Heck (trad) Ponto Alegre: Sérgio Autonio Fabris, 1998, p.180-184

24 Estado federal brasileiro foi implantado pelo Decreto 1 de 15 de novembro de 1889 . O federalismo de 1891 foi o dualssta ou centrífugo onde os Estados membros tinham vasta autonomia. Para Constituição de 1934 surge o novo federalismo, o cooperativo. Com o golpe de 1937, advém o federalismo meramente nominal. A Constituiçăo de 1946 restaurou o federalismo cooperativo que a Constituição de 1967 conservou com expansão dos poderes da União, consagrando un federalismo centrípeto e, enfirm, a Constitução de 1988 , emantido o federalismo cooperativo con limites aos poderes federais corrigindo distorçoes. Perfil histórico do federalimo brasileiro com apoio cm Raul Machado Horta, Luiz Roberto Barroso e Carlos Mario da Silva Velloso, apad VALADÃO, Marcos Aurélio Pereira. Limitaçōes ao poder de tributar e tratados intetnacionais. Belo Horizonte: Del Rey, 2000, p. 130. 
dividido em 16 capitanias que foram denominadas províncias. Em 1817 , foi criada a província de Alagoas; em 1820, a de Sergipe. O Império surgiu com 18 províncias. Posteriormente, foram criadas as do Amazonas, antiga Comarca de Alto do Rio Negro; e a do Paraná em 1853, perfazendo um total de 20 províncias que foram transformadas em Estados-membros com o advento da Federação ${ }^{25}$.

Estabelecidas tais colocações, Osvaldo Ferreira de $\mathrm{Melo}^{26}$ conclui que as mesmas 20 províncias do Império formam os Estados-membros da Primeira República. A Constituição de 1891 definiu com precisão a competência e a autonomia política dos Estados, bem como sua participação na vontade nacional.

Chega-se, enfim, ao início da colonização brasileira, que constituiu um presságio da dificuldade de adaptação do pacto federal no Brasil, face à dispersão de interesses na sua estrutura organizacional ${ }^{27}$. Tem-se que o regime federativo pode provir de duas origens diversas, de um tratado acordado entre antigos Estados soberanos e independentes, a exemplo do caso clássico dos Estados Unidos, ou de um movimento histórico de cunho nacional, como no Brasil em 1889, que de regime monárquico e unitário passou a uma república federativa ${ }^{28}$.

Vê-se, portanto que o caso do Brasil, como Estado federal, decorreu de um movimento histórico e da desagregação e isso refletir-se-á nas competências dos entes federados.

Enfim, o Estado brasileiro tem a forma federativa, sob o comando de um governo republicano, tem estrutura tríplice, formado pela União, por Estados, pelo Distrito Federal e por Municípios, todos autônomos ${ }^{29}$. Têm-se como características do Estado federal a participação dos Estados-membros no governo central através de seus representantes no Congresso; autonomia (auto-organização) e descentralização política, administrativa e legislativa. O Estado federal existe porque há partilha interna de competências, tendo o poder constituinte da federação, reservada a

\footnotetext{
25 LOPES, Aparecido Domingos Errerias. O federalismo fiscal no Brasil. 1979. Dissertação (Mestrado em Ciências Humanzas - especialista em Direito) - Curso de Pós Graduação em Direito, Universidade Federal de Santa Catarina, Florianópolis. p.6.8

* MELO, Osvaido Ferreira de. Tendências do federalismo no Brasil. Florianópolis: Lunardelli, 1975.

27. COSTA, Gustavo de Freitas Cavalcanti. Federalismo \&. ICMS: reflexos tributários. Guritiba: Juruá, 2000.p.31

2* FERREIRA, Pinto. Principios gerais do Direito constitucional moderno. 4 ed. Săo Paulo: Saraiva, 1962. vol.2, p.622.

29 Art. 18 da Constituiçăo Federal. A organização politicoadmnistrativa da República Federativa do Brasil compreende a Uniăo, os Estados, o Distrito Federal e os Municipios, todos autônomos, nos termos desta Constituição.
} 
competência constitucional específica de constituir a unidade federada, cabendo ao Poder Legislativo, regra geral, editar as regras jurídicas.

Com efeito, o Brasil é uma federação e isso exige que se atribua um imposto onde a arrecadação dos entes que compõem a federação supra as suas necessidades.

Enfim, a concepção de federação pressupõe repartição de competências, legislativa e material, autonomia política organizacional e financeira ${ }^{30}$.

Alude-se a um dado instante, competência, segundo discorre Élcio Fonseca Rei $^{31}$ é a medida da capacidade de ação política ou administrativa, legitimamente conferida a um órgão, agente ou poder, nos termos juridicamente definidos.

$O$ federalismo fiscal origina a existência de diferentes esferas de governo, a repartição de competências e das receitas tributárias que são fontes de situações que se referem à Economia, ou sejam, repartiçăo das fontes de receita e de encargos entre as jurisdições e as relações intergovernamentais em matérias fiscal e financeira. De fato, o federalismo fiscal traz vantagens como a racionalidade das decisões referentes às despesas relativas à proximidade com a autoridade que ordena as despesas e coletividade que as demanda; menor custo administrativo que a administração centralizada; melhor oferta de serviços públicos. Porém, apresenta desvantagens como a descentralização do sistema arrecadatório; tendência de agravar as situações regionais; guerra fiscal; limitação do uso extrafiscal da tributaçâo ${ }^{32}$.

Como pode-se constatar, quando diz respeito ao federalismo fiscal, vislumbra-se um deslocamento do poder político de um único centro emanado para outros centros periféricos para uma melhor satisfação de anseios regionais ou locais, no intuito de atribuir um conjunto de competências a esses entes federados, acompanhado de mecanismo ou meios aptos a conferir a autonomia necessária, inclusive a financeira.

Afinal, tratar de autonomia financeira é enunciar a captação de recursos financeiros, a arrecadação de tributos. Para se evitar que em conseqüência da atribuição de competências advenham um aumento de tributos, faz-se necessária a repartição de receitas de forma justa e racional, sem enfraquecer o pacto federativo. Enfim, a falta de equilibrio da equação político-financeira deixa a federação fragilizada porque a autonomia política tem estreita relação com a capacidade de auto suficiência.

\footnotetext{
* REIS, Elcio Fonseca. Federalismo fiscal: competência concorrente e normas gerais de Direito tributenio. Belo Horizonte: Mandaxmentos, 2000, p, 203

3 Ibidem, p. 4243

32 VALADAO, Marcos Aurélio Pereira. Limitaçóes ao poder de tributar e tratados intenacionats. Belo Horizonte: Del Rey, 2000, p.126 


\section{Conclusão}

Além das disposições constitucionais propugnadas na Carta Política de 1988, de que a União não poderá conceder isenções de tributos de competência distrital, estadual e municipal (art. 151-III), deve ser considerado que com o Tratado de Assunção, firmado em 1991, o MERCOSUL é uma realidade da qual, não se pode deixar para segundo plano, no tocante ao aspecto da harmonização da legislação tributária. Da mesma forma há necessidade de alterar a legislação tributária brasileira face aos demais tratados internacionais firmados com outros blocos econômicos.

A questão aduaneira passa primeiro pelo estabelecimento de uma política fiscal e, caminha para um consenso tributário entre países com problemas tão graves e de dimensões tão diversas. É inicialmente um grande desafio. Tal reforma não apenas da legislação ordinária e sim, há necessidade de uma reforma constitucional, para melhor adequar o Sistema Tributário, para diminuir as distorções existentes entre o Brasil e os sistemas tributários dos outros países do MERCOSUL, de outros blocos econômicos seguindo as tendências internacionais.

A prevalência dos tratados internacionais em relação ao direito interno não quer dizer prevalência total sobre a ordem jurídica brasileira. Pelo contrário, a matéria vedada em tratados internacionais somente afeta o ordenamento pátrio na medida em que o Congresso Nacional aprova o ato do Presidente da República, que não seja contrário à Constituição Federal, devendo ser proporcionalmente consideradas as disposiçōes do artigo 98 do CTN.

Além da reforma estrutural do sistema tributário brasileiro, tanto a globalização, quanto a regionalização da economia, requererão transformações muito mais profundas na ordem constitucional brasileira, especialmente no que tange ao sistema tributário, alterando a repartição das competências com a unificação do IVA (Imposto sobre o Valor Agregado).

A experiência européia poderá ser útil. A instituição do Tribunal de Justiça europeu verificou-se quando da condições sócio-econômicas revelaram tal necessidade. Novas implantações ou ajustes no sistema jurídico do MERCOSUL deverão ser feitas de forma amadurecida e adequadas às reais necessidades que atendam os interesses dos países signatários. 
Assim, o desafio da harmonização tributária está em buscar um razoável equilíbrio entre a soberania e submissão do sistema estatal com a diminuição ou supressão das barreiras alfandegárias. ${ }^{33}$

É pacífica a necessidade de adaptação dos sistemas tributários à nova realidade econômica, face à globalização. Quais seriam, então, as alternativas disponíveis para as autoridades tributárias de cada país? O expressivo crescimento do comércio exterior brasileiro, aliado à necessidade de se buscar uma maior participação do País no comércio mundial, tem exigido a adequação da aduana nacional.

A legislação tributária brasileira tem se adaptado gradativamente ao fenômeno da globalização, assim como a administração tributária tem buscado adequar seus procedimentos. Como exemplo, podem-se citar várias alterações realizadas no âmbito do Imposto de Renda das Pessoas Jurídicas, de modo a adequá-lo à nova realidade econômica. Dentre elas, destacam-se a introdução do mecanismo de tributação mundial da renda e a aprovação de legislação relativa a preços de transferência.

Outra modificação da legislação tributária brasileira, diretamente relacionada com a soberania tributária, diz respeito ao tratamento legal dos preços de transferência, conforme mencionado. Desde 1997, foram estabelecidos procedimentos para o controle da prática e da manipulação de transações realizadas entre empresas transnacionais vinculadas. A legislação brasileira, a partir do referido ano, introduziu importante medida referente à concessão de tratamento diferenciado aos países com tributação favorecida. Aplicam-se, assim, as mesmas disposições relativas aos preços de transferência às operações efetuadas por pessoa física ou jurídica residente ou domiciliada no Brasil com qualquer pessoa física ou jurídica, ainda que não vinculada, residente ou domiciliada em país que não tribute a renda, ou que a tribute à alíquota máxima inferior a vinte por cento. Esse dispositivo é um dos instrumentos para coibir ou diminuir a utilização de paraísos fiscais como forma de elisão ou evasão tributárias.

Em síntese, a divergência existente entre os sistemas impositivos mostra que a redução da soberania de cada país, como conseqüência da competição tributária, é um processo de longo prazo. No entanto, a

33 O temor de que um país perca sua soberania ao participar de um processo integracionista é infundada e irreal, vez que muitos países, atualmente, entre eles o Brasil, possuem apenas uma soberana virtual. Talvez o processo de integração venha justamente aprofundar laços e fortalecer regiões que antes estavam sob o jogo de interesses alienígenas, puramente exploradores. Cf. MATA, DIZ, Jamile Bergamaschine. Harmonização Tributária no MERCOSUL $\mid$ : Da utopia à realidade, in Revista de Informação Legislativa, Brasilia, ano 37, n. 146, abril/junho, 2000, p. 202. 
harmonização tributária sempre será necessária como um instrumento que possa garantir práticas leais de competição internacional e de sistemas impositivos, efetivamente adequados à economia globalizada.

A soberania tributária não está ligada, necessariamente, ao conceito de soberania territorial. O Estado tem soberania fiscal quando edita suas leis, quando a sua vontade é a última a prevalecer, quanto aos seus administrados, e, igualmente, como já mencionado, a soberania fiscal ultrapassa o território do Estado, quando sua competência tributária alcança seus contribuintes onde quer que ele esteja.

\section{BIBLIOGRAFIA}

ACCIOLY, H. Manual de Direito internacional público. 11ed. São Paulo: Saraiva, 1991. 9a tiragem. Revista por Geraldo Eulálio do Nascimento e Silva

CARTOU, L. Droit fiscal international et européen. 2ed. Paris: Précis Dalloz, 1986

CLOSA, C. Sistema político de la Unión Europea. Madrid: Complutense, 1997.

COSTA, G. F. C. Federalismo \& ICMS: reflexos tributários. Curitiba: Juruá, 2000.

DALLARI, P. Constituição e relações exteriores. São Paulo: Saraiva, 1994 DINH, N. \& DAILLIER, P \& PELLET, A Direito internacional público. trad. por Vitor Marques Coelho, Lisboa: Fundação Calouste Gulbekian, 1999. DIZ, J. B. M. Harmonização Tributária no MERCOSUL|: Da utopia à realidade, in Revista de Informação Legislativa, Brasilia, ano 37, n. 146, abril/ junho, 2000

FALCÃO, M. A Elementos de reflexão para harmonização tributária no Mercosul. Monografia cedida pelo autor, vencedora do Mercoprêmio legislação em 2000

FERNANDES, E. Normas Tributárias do MERCOSUL in O Direito Tributário no MERCOSUL, Forense, RJ, 2000.

FERREIRA, P. Princípios gerais do Direito constitucional moderno. 4 ed. São Paulo: Saraiva, 1962. vol.2

GRUPENMACHER, B. T. Tratados internacionais em matéria tributária e ordem interna. São Paulo: Dialética, 1999

HESSE, K. Elementos de Direito constitucional da República Federal da Alemanha. Luis Afonso Heck (trad.) Porto Alegre: Sérgio Antonio Fabris, 1998

LOPES, A D. E. O federalismo fiscal no Brasil. 1979. Dissertação (Mestrado em Ciências Humanas - especialista em Direito) - Curso de Pós Graduação 
em Direito, Universidade Federal de Santa Catarina, Florianópolis.

MELLO, C. D. A Curso de Direito internacional público. $11 \mathrm{ed}$. rev. aum. Rio de Janeiro: Renovar, 1997. vol. 1

MELO, J. E. S. ICMS teoria e prática. 4 ed. atualizada com a LC 102/2000. São Paulo: Dialética, 2000

MELO, O F. Tendências do federalismo no Brasil. Florianópolis: Lunardelli, 1975.

MORATI, Constantino. Instituzioni di diritto pubblico. 7 ed. Padova: Cedam, 1968, v.2

OLIVEIRA, O M. Relações internacionais: estudos de introdução. Curitiba: Juruá, 2001.

PIMENTEL, Luiz Otávio. Cenário internacional, Direito e sociedade no processo de mundialização. In.: Mercosul no cenário internacional: Direito e Sociedade. Curitiba: Juruá, 1998, vol.2.

REIS, E F. Federalismo fiscal: competencia concorrente e normas gerais de Direito tributário. Belo Horizonte: Mandamentos, 2000.

REIS, Elcio Fonseca. Federalismo fiscal. Belo horizonte: Mandamentos, 2000.

ROTHAMAN, Gerd Willi. Considerações sobre extensão e limites do poder de tributar. NOGUEIRA, Ruy Barbosa (org.) Estudos tributários. São Paulo: Resenha Tributária, 1974

SILVA, R. L. X Encontro de Estudantes de Direito do MERCOSUL sobre: Da Análise da Soberania Estatal sob o prisma do Direito Comunitário e da Integração, publicado nos Anais, UNIFIL, Londrina, 2002

TORRES, H. Pluritributação internacional sobre as rendas de empresas. 2 ed. rev, atual. e ampl. São Paulo: Revista dos Tribunais, 2001

VALADÃO, M A P. Limitaçōes ao poder de tributar e tratados internacionais. Belo Horizonte: Del Rey, 2000

VILLEMOT, Dominique. L'harmonasition fiscale européenne. Paris: Presses Universitarires de France, 1995. 